\title{
Sustained acoustic medicine as a non- surgical and non-opioid knee osteoarthritis treatment option: a health economic cost- effectiveness analysis for symptom management
}

Thomas M. Best ${ }^{1 *}$, Stephanie Petterson ${ }^{2}$ and Kevin Plancher $2,3,4,5$

\begin{abstract}
Background: Patients diagnosed with osteoarthritis $(\mathrm{OA})$ and presenting with symptoms are seeking conservative treatment options to reduce pain, improve function, and avoid surgery. Sustained acoustic medicine (SAM), a multihour treatment has demonstrated improved clinical outcomes for patients with knee OA. The purpose of this analysis was to compare the costs and effectiveness of multi-hour SAM treatment versus the standard of care (SOC) over a 6-month timeframe for OA symptom management.
\end{abstract}

Methods: A decision tree analysis was used to compare the costs and effectiveness of SAM treatment versus SOC in patients with OA. Probabilities of success for OA treatment and effectiveness were derived from the literature using systematic reviews and meta-analyses. Costs were derived from Medicare payment rates and manufacturer prices. Functional effectiveness was measured as the effect size of a therapy and treatment pathways compared to a SOC treatment pathway. A sensitivity analysis was performed to determine which cost variables had the greatest effect on deciding which option was the least costly. An incremental cost-effectiveness plot comparing SAM treatment vs. SOC was also generated using 1000 iterations of the model. Lastly, the incremental cost-effectiveness ratio (ICER) was calculated as the (cost of SAM minus cost of SOC) divided by (functional effectiveness of SAM minus functional effectiveness of SOC).

Results: Base case demonstrated that over 6 months, the cost and functional effectiveness of SAM was $\$ 8641$ and 0.52 versus SOC at: $\$ 6281$ and 0.39 , respectively. Sensitivity analysis demonstrated that in order for SAM to be the less expensive option, the cost per 15-min session of PT would need to be greater than $\$ 88$, or SAM would need to be priced at less than or equal to $\$ 2276$. Incremental cost-effectiveness demonstrated that most of the time (84\%) SAM treatment resulted in improved functional effectiveness but at a higher cost than SOC.

(Continued on next page)

\footnotetext{
* Correspondence: thom.m.best@gmail.com

'Department of Orthopedics, UHealth Sports Medicine Institute, University of Miami, Coral Gables, FL, USA

Full list of author information is available at the end of the article
}

C C The Author(s). 2020 Open Access This article is licensed under a Creative Commons Attribution 4.0 International License, which permits use, sharing, adaptation, distribution and reproduction in any medium or format, as long as you give appropriate credit to the original author(s) and the source, provide a link to the Creative Commons licence, and indicate if changes were made. The images or other third party material in this article are included in the article's Creative Commons licence, unless indicated otherwise in a credit line to the material. If material is not included in the article's Creative Commons licence and your intended use is not permitted by statutory regulation or exceeds the permitted use, you will need to obtain permission directly from the copyright holder. To view a copy of this licence, visit http://creativecommons.org/licenses/by/4.0/ The Creative Commons Public Domain Dedication waiver (http://creativecommons.org/publicdomain/zero/1.0/) applies to the data made available in this article, unless otherwise stated in a credit line to the data. 
(Continued from previous page)

Conclusion: In patients with osteoarthritis, SAM treatment demonstrated improved pain and functional gains compared to SOC but at an increased cost. Based on the SAM treatment ICER score being $\leq \$ 50,000$, it appears that SAM is a cost-effective treatment for knee OA.

Keywords: Osteoarthritis, Sustained Acoustic Medicine, Physical therapy, Socio-economical impact, Cost-effect analysis, Health care cost

\section{Introduction}

Osteoarthritis (OA) is the most common type of arthritis affecting over 63 million adults in the USA annually [1]. The most common presentation of $\mathrm{OA}$ is in the knee, occurring in $10-13 \%$ of men and women over the age of 60 with an estimated 14 million people having this condition $[2,3]$. The prevalence of $\mathrm{OA}$ is projected to increase as people become more obese and the population skews towards older age. $\mathrm{OA}$ is characterized by joint inflammation with chronic pain and decreased function of the joint as stiffness and swelling limit mobility. ${ }^{4}$ In turn, quality of life and productivity are adversely affected [3, 4].

Pain from OA is one of the key reasons why patients seek medical care and generally precedes disability/loss of function [5]. As the pain worsens, the treatments first focus on pain relief and the inflammatory aspects of the disease [6]. In recent years, there has been an increasing emphasis on non-pharmacologic therapies to treat the symptoms of OA including physical therapy, exercise, massage, and ultrasound which for most are not as easily accessed due to patients lacking the resources or ability to do so, ultimately contributing to worse pain and greater disability [7]. Recent recommendations by the American College Rheumatology (ACR)/Arthritis Foundation for treating knee OA call for a comprehensive plan including the above therapies which may be used in sequence, again depending upon pain severity [8].

The effectiveness of ultrasound as a therapy for OArelated pain and disability has been substantiated in a number of systematic reviews and meta-analyses [9-12]. However, one of the challenges with current ultrasound delivery is that reimbursement requires administration via constant attendance by a care provider in a professional setting, generally for a short duration of time (5$10 \mathrm{~min}$ ) over approximately a 30 -day period. This is likely due to the types of high quality studies that have examined this condition and associated treatment protocols as well as payer policies, which only cover for direct one-on-one constant attendance by a provider [13-15]. The policies and in-office treatment requirement prohibits daily treatment in the clinical setting for many patients and medical professionals. Despite the short duration of in-clinic ultrasound treatment, residual positive effects on pain and function with this modality appear to last upwards of 1 year [16, 17]. Recently, daily, multi-hour sustained acoustic medicine (SAM), lowintensity, long-duration wearable ultrasound has been found to provide effective pain relief and functional improvement in patients with knee OA [18-23].

It is with the above in mind that a cost-effectiveness analysis was undertaken to examine accepted treatment pathways in using SAM ultrasound versus standard of care (SOC) in the relief of knee OA pain and improvement of function over a 6 -month period. The reason 6 months was chosen is that all generally accepted therapies for pain relief could be evaluated, with the intention that therapies that improve function could then be evaluated. The purpose was to examine the overall direct costs for care in using one therapy versus another and to examine the outcome of the patient. Additionally, the SAM ultrasound therapy system that can be used in the home over long durations without direct one-on-one provider contact was evaluated. To our knowledge, such an analysis has not been previously conducted.

\section{Methods}

The patients evaluated in the model presented with pain characterized as intense, unpredictable, and emotionally draining resulting in the avoidance of physical activity [24]. In other words, the pain was severe enough such that there was an avoidance of physical therapy, which has consistently been shown to improve function [25]. This type of pain is also distressing enough that it affects the person's quality of life, limiting activities of daily living and other recreational activities [16]. Additionally, these patients were $<65$ years of age (i.e., non-Medicare).

The clinical guidelines used for treatment of knee OA in this assessment were the 2019 ACR/Arthritis Foundation guidelines for the management of OA of the hand, hip, and knee [8]. All therapies recommended by the ACR were used in the model. However, one therapy that was not recommended by the ACR was also used, hyaluronic acid (HA) injections (ACR has a conditionally recommended against for $\mathrm{HA}$ ) [8]. Inclusion of HA use was due to the identification of a 2009 Cochrane Review on viscosupplementation where HA was supportive of its use for relieving pain [25]. 
Identification of the highest quality of evidence was used in the evaluation of outcomes for pain relief and function for all therapies. The types of studies identified therefore were systematic reviews and meta-analyses. PubMed and Cochrane Library were the databases searched with the key words used for identifying studies being:

$((()((()((()($ systematic) AND review) AND metaanalysis) AND pain) AND knee) AND osteoarthritis) AND outcome)) AND function)) AND random*) AND

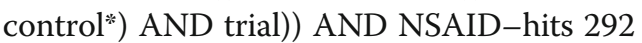

$\iota_{(()((()((()((\text {systematic })}$ AND review) AND metaanalysis) AND pain) AND knee) AND osteoarthritis) AND outcome)) AND function)) AND random*) AND control*) AND trial $)))$ AND physical therapy-hits 1,174.

${ }^{(}((()(()((()(((($systematic) $)$AND review) AND metaanalysis) AND pain) AND knee) AND osteoarthritis) AND outcome)) AND function)) AND random*) AND

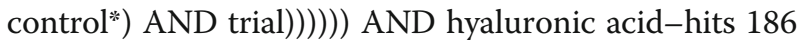

${ }_{(()(()(()(()(()(()(()(\text {systematic })}$ AND review) AND meta-analysis) AND pain) AND knee) AND osteoarthritis) AND outcome)) AND function)) AND random*)
AND control*) AND trial())) )) ))) )) AND steroid) AND injection*-hits 211

$(()(()((()(()(()(($ systematic $)$ AND review) AND metaanalysis) AND pain) AND knee) AND osteoarthritis) AND outcome)) AND function)) AND random*) AND

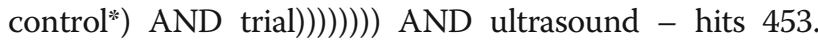
Figure 1 identifies the process of identifying the systematic review and meta-analyses used in the current analysis.

In order to simplify the model and not introduce confounding therapies, the assumption was made that therapies were used sequentially for both SAM treatment and SOC based on ACR care guidelines. In other words, if a therapy improved upon pain enough (with pain being the limiting factor for engaging in PT) such that PT could be initiated, it ended the decision to use another pain therapy. However, if pain was not improved, another modality was employed. The probability of improvement in pain such that PT could be initiated was identified in the systematic reviews and meta-analyses identified in the searches [25-28].

Costs were derived from manufacturer pricing [29], reimbursement rates over last 3 years for the SAM device

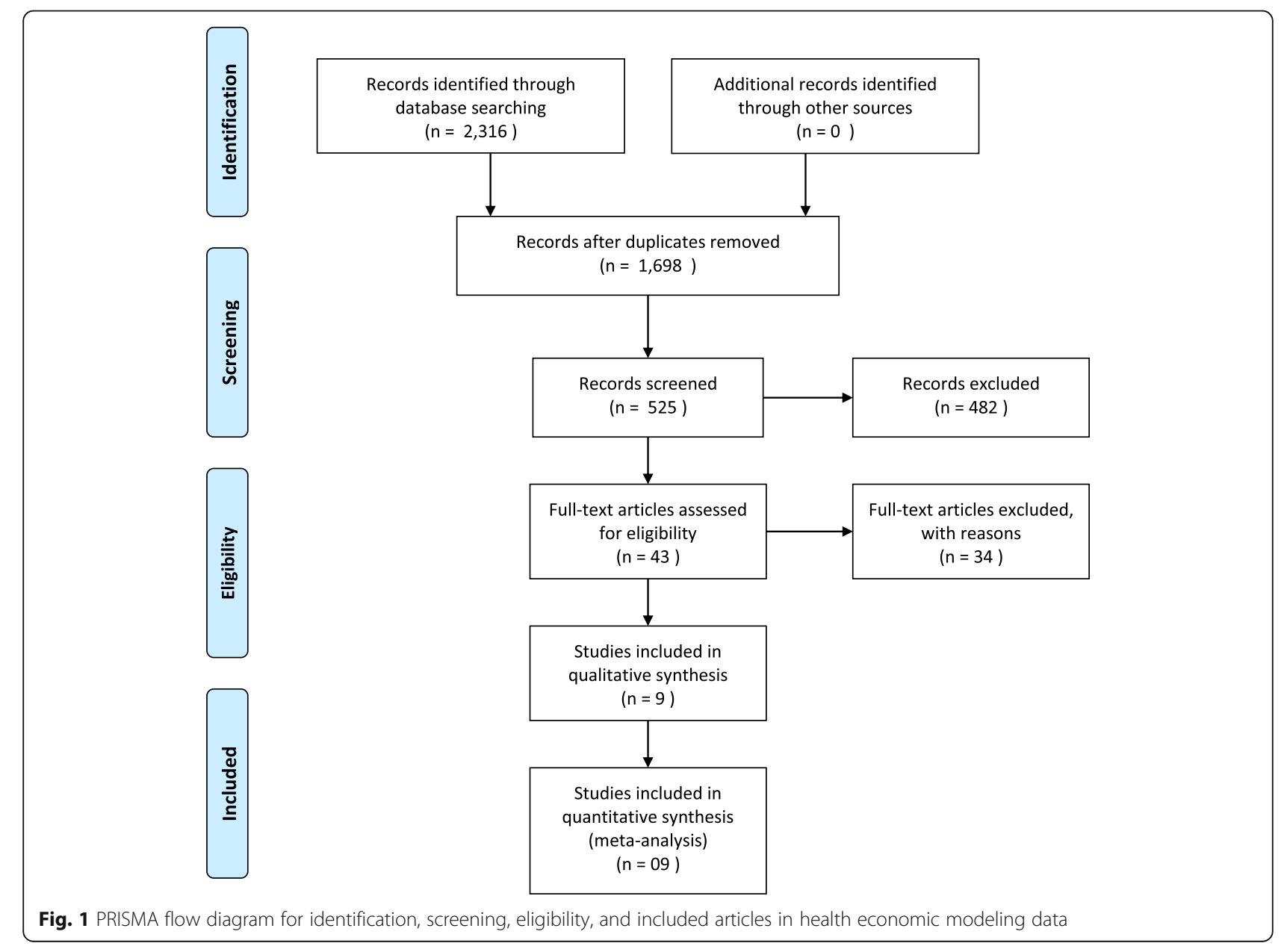


including federal agencies TRICARE Military and VA Health System [30], and from 2020 National Medicare rates adjusted by the ratio of Medicare payments to commercial payments in order to obtain the commercial rates $[31,32]$.

Lastly, the statistically significant effect sizes for a therapy in improving pain relief and function were identified in the systematic reviews and meta-analyses [27, 33, 34]. The effect size is a simple way of quantifying the size of a difference between 2 groups. An effect size of greater than 0.5 generally means that the difference is important and can be observable which was used in the model [35]. It was further assumed that when PT was initiated (based on pain improvement), it was continued for the duration of the 6-month analysis as PT has been shown to have a positive effect on function over time [36]. The number of sessions and duration (e.g. dosing) was derived from the medical literature whereby the largest effect could be identified [36].

Pain and function were established endpoints of the model as they are arguably of the most important outcomes in patients with knee OA. The American Academy of Orthopedic Surgeons (AAOS) has stated that: "the quality and success of interventions to treat OA should be assessed based on outcomes deemed to be of importance to the patient. "[37]. The measure of pain and function in knee OA has also been established as part of the physician quality reporting system (PQRS \#109) [38].

The incremental cost-effectiveness ratio (ICER) was used in measure improvement of pain and function, and has been used in the past in knee OA for determining the ICER of a therapy [39]. Pain and function have been recognized as important outcome measures by the Institute of Clinical Economic Review, a leading organization in the area of value analysis of therapies [40]. For this particular analysis, the ICER was calculated as follows: (cost of SAM treatment minus cost of SOC)/(functional effectiveness of SAM minus functional effectiveness of SOC).

Tree Age Pro Healthcare 2020 software (TreeAge Software Inc., Williamstown, MA, USA) was used in the analysis. The variables, distributions and equations used in the model are found in Appendix 1 and 2. The decision tree is found in Fig. 2. Additionally, a tornado plot was employed to determine which variables in the model had the greatest effect on costs such that one therapy was found to be less expensive than the other. These variables were then examined individually in sensitivity analysis to identify the value at which one therapy became more expensive relative to the other and whether this value was realistic in everyday practice. An ICER scatterplot was also evaluated whereby the variables in the model were randomly varied 1000 times using the low and high values as identified in the variables/distributions (Appendix 1).

Lastly included in the model, and as mentioned above, a wearable, long duration, continuous home-use ultrasound system that is self-administered, and capable of delivering $18,720 \mathrm{~J}$ of ultrasound therapy for up to $4 \mathrm{~h} /$ day generating vigorous deep musculoskeletal diathermy $\Delta 8{ }^{\circ} \mathrm{C}$ at $1 \mathrm{~cm}, \Delta 6^{\circ} \mathrm{C}$ at $3 \mathrm{~cm}, \Delta 3^{\circ} \mathrm{C}$ at $5 \mathrm{~cm}$; and allows a patient to utilize ultrasound therapy outside of a medical facility (Sustained Acoustic Medicine [SAM] device, FDA Approval \# K191568, ZetrOZ Systems, LLC, Trumbull, CT, USA). This device has been used safely and effectively in the treatment of knee OA [20-23] chronic myofascial pain [41-43], tendinopathies [44-47], and for healing various musculoskeletal injuries [19, 22, 44-47]. Markov modeling (1000 iterations) was used to examine on a percentage basis were SAM treatment would be a more effective and more costly therapy versus SOC.

\section{Results}

In the initial knee OA care pathway of the model shown in Fig. 2, the cost and effect size on pain and function over 6 months was $\$ 8641$ and 0.52, respectively for SAM treatment and $\$ 6282$ and 0.39 , respectively for SOC. Thus, the ICER for the use of SAM was $\$ 18,146$ (\$8641 less $\$ 6282) /(0.53$ less 0.39). In the later stage, knee OA care pathway with response to SAM with the addition of PT the cost and effect size was $\$ 13,967$ and 0.77 , respectively, versus SOC combined with NSAIDs and PT at $\$ 9294$ and 0.47 , respectively. The later care pathway SAM ICER value was $\$ 15,576$ (\$13,967 less $\$ 9,294) /(0.77$ less 0.47).

A tornado plot (Fig. 3) identified the following variables which had the greatest effect on cost (i.e., in identifying SAM as the least costly option) including the cost of SAM, cost of a 15-min PT session, and the number of PT sessions. Additional sensitivity analysis identified the following variables and their threshold values were SAM treatment becomes the less costly alternative (Table 1).

In order for SAM treatment to be the less expensive option relative to SOC, it would need to cost $<\$ 2276$ (Fig. 4). The price of SAM treatment used in the model is $\$ 4635$ (average reimbursement price of the unit). For SAM treatment to be the less expensive option, the cost of PT would need to be $>\$ 88$ per 15 -min session (Fig. 5). It is assumed in the model that the cost per 15-min PT session was $\$ 41.80$ and that a patient would receive anywhere from 2 to 4, 15-min sessions per visit. Or in order for SAM treatment to be the less expensive option, > 144 total sessions (15-min per session) would need to occur (Fig. 6). Lastly, Fig. 7 demonstrates in Markov modeling that $84 \%$ of the time SAM treatment was more effective in pain and function outcomes for knee OA versus SOC pathway, and a more costly therapy versus SOC over 6 


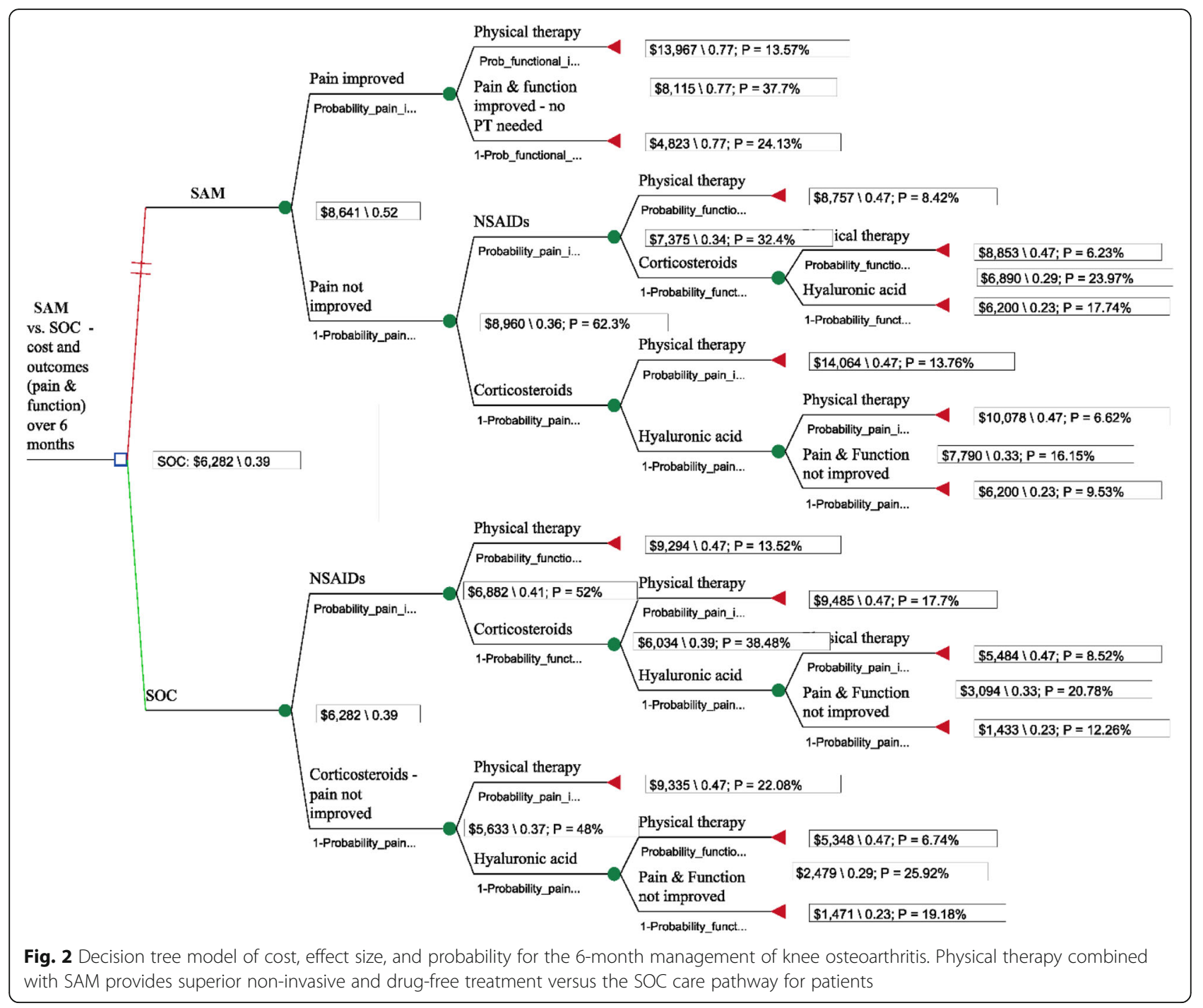

Fig. 2 Decision tree model of cost, effect size, and probability for the 6-month management of knee osteoarth
with SAM provides superior non-invasive and drug-free treatment versus the SOC care pathway for patients

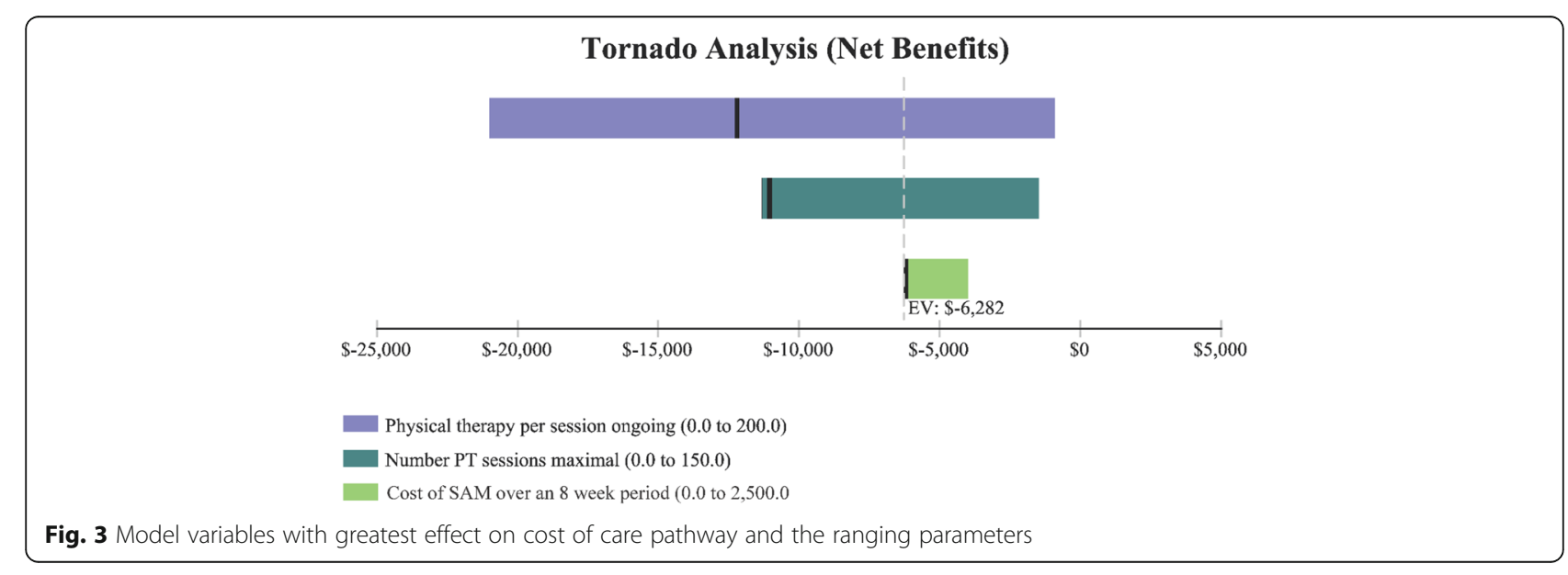


Table 1 Cost-effectiveness model variables where SAM treatment of knee osteoarthritis becomes less costly. Each model variable is independent based on the base model assumptions

\begin{tabular}{lll}
\hline Variable & Value at which SAM treatment becomes the less costly alternative & Figure \\
\hline SAM treatment cost & $<\$ 2276$ & Fig. 4 \\
Cost for PT per session & $>\$ 88$ & Fig. 5 \\
Number of 15 min PT sessions & $>144$ & Fig. 6 \\
\hline
\end{tabular}

months of treatment. The centroided of the Markov model demonstrates an incremental cost of $+\$ 2400$ and effect of +0.12 for SAM treatment of knee OA.

\section{Discussion}

The major finding from our analysis was that the home-use SAM device for the treatment of OA pain and subsequent improvement in function and quality of life was costeffective with an ICER between $\$ 15,576$ and $\$ 18,146$. The calculated SAM ICER value range falls within accepted cost-effectiveness threshold values in determining whether a therapy is cost-effective. The Institute for Clinical and Economic Review considers ICERs of \$50,000-\$100,000 high value care [40]. Payer organizations such Premera Blue Cross of Washington identify therapies as cost-effective if they are between the values of $\$ 10,000-\$ 50,000$ [48]. Specialty societies such as the American College Cardiology identify high value care as an ICER $<\$ 50,000$ [48]. Lastly, cost-effectiveness systematic reviews for the surgical management of OA including procedures covered by Medicare have ICER values \$10,000-\$100,000 [49].

Reduction of pain and increased function are important outcomes for patients with knee OA and are commonly used as endpoints in studies examining therapies for treating this disease [49]. These endpoints are observable, measurable, and most relevant to the patient [37]. It has also been identified that function is highly correlated with quality of life (QoL) in patients with knee OA [50-52], another endpoint evaluated in our ICER analyses. Thus, the use of function as well as pain as an outcome in ICER appears to be a good proxy for QoL and are commonly used [53].

Widespread use of traditional ultrasound in treating both pain and improving function of patients is hampered by the requirement that it has traditionally been limited to us in a clinical setting, is of short duration, and must be applied by a clinician with direct provider to patient contact [13-15] These limitations are further enhanced by the recent 2020 pandemic which has reduced patient access to clinical practices and has resulted in new remote care policies being issued by insurance carriers and governmental agencies [54, 55]. Other limitations include specialty societies and payers in making recommendations for ultrasound treatment of knee OA or lack thereof $[8,56-58]$. Unfortunately, some payer coverage and utilization policies have not been updated for over 10 years, failing to account for recent, high quality evidence in establishing coverage determinations $[13,14,58]$. Additionally, there appears to be an issue with the use of office-based ultrasound devices causing harm (e.g., burning and overexposure) if the ultrasound head is not moved constantly over the affected site $[18,19]$. However, recent high quality studies of FDA-cleared home use of low intensity long duration SAM ultrasound for symptomatic relief of knee OA have

\section{Sensitivity Analysis (WTP=0)}

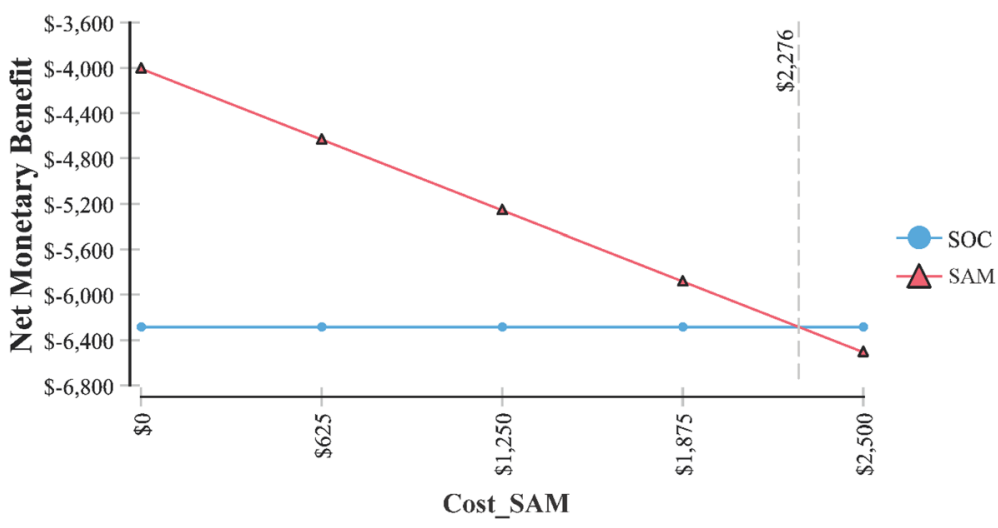

Fig. 4 Sensitivity analysis on SAM cost where treatment is less expensive option to SOC 


\section{Sensitivity Analysis $(\mathrm{WTP}=\mathbf{0})$}

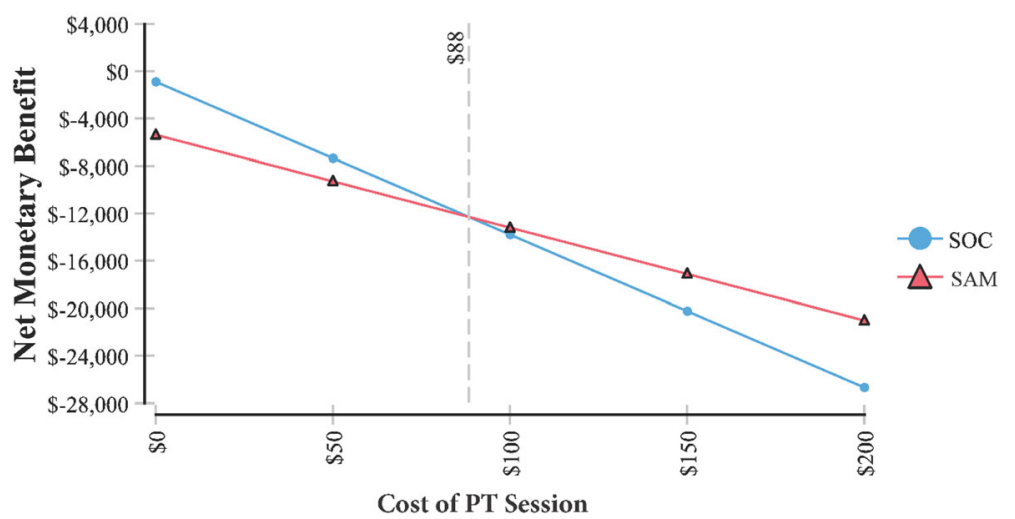

Fig. 5 Sensitivity analysis relative to PT session costs, where SAM treatment costs less than SOC

demonstrated similar efficacy to clinical setting use [20]. Two earlier pilot studies and two RCTs demonstrated similar findings for this type of SAM treatment for knee OA [21, 22]. Long duration continuous SAM ultrasound has demonstrated good safety with unattended use in the home and work setting [18, 20-23, 41-44, 46, 59-61].

Recent studies have identified that greater than $25 \%$ of patients with knee OA use opioids and that increased pain severity increases their use [62, 63]. Further, it has been found that the use of opioids for pain relief significantly increases the downstream costs (either alone or concomitantly with PT) vs. PT only [64]. Lastly, what is interesting to note is that the timing of nonpharmacological therapies (i.e., early vs. later in the diagnosis of knee OA) results in a lower usage of opioids, likely due to a patient experiencing pain reduction [65]. A non-invasive therapy such as SAM used early in the diagnosis and in the home could lessen the use of opioids, and possibly help with the current epidemic of overuse/over prescribing [66]. Since opioid treatment was not considered as an option in the current analysis (only topical NSAIDs), it is a limitation of this analysis. For this very reason, however (i.e., minimizing the need for opioid use), SAM treatment should be considered a viable, prescribed, and covered home therapy.

It is interesting to note from the sensitivity analysis that for SAM treatment to be a less costly alternative compared to SOC, it would need to be less than $\$ 2276$. The model uses a price of $\$ 4635$, which is the reimbursement price of the equipment evaluated in the model. A patient owning the equipment could lead to more extended use in the home, alleviating the need to visit a clinician and the costs associated with travel to and from a clinical setting for the patient and; additional follow-on care longer term.

The assumed cost for PT used in the model was $\$ 41.80$ per $15 \mathrm{~min}$. It was found in our sensitivity analysis that for SAM to be the less expensive option that

\section{Sensitivity Analysis (WTP=0)}

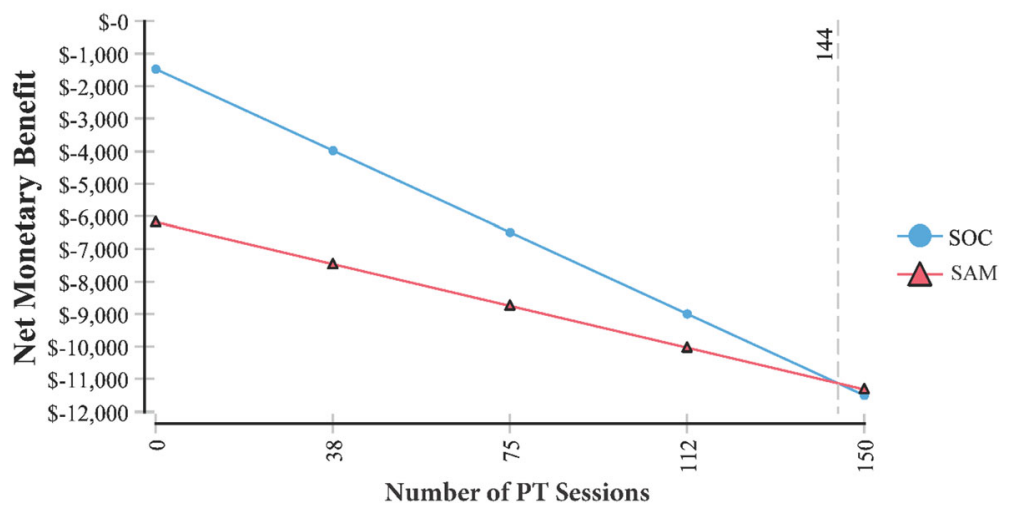

Fig. 6 Sensitivity analysis relative to the number of PT sessions where SAM treatment costs less than SOC 


\section{Incremental Cost-Effectivness, SAM vs. SOC}

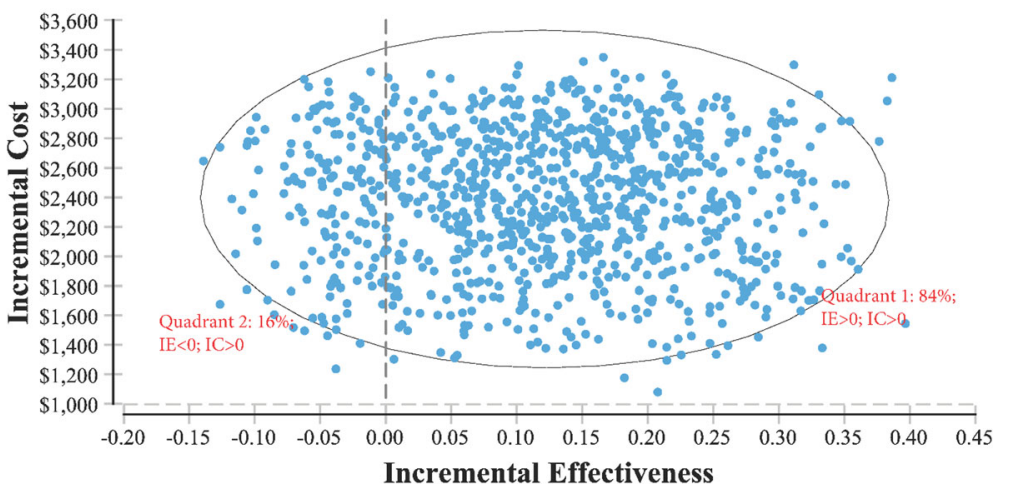

Fig. 7 Markov modeling scatter plot of cost effectiveness for SAM treatment versus SOC

this cost per 15 min would need to be greater than $\$ 88$. Therefore, SAM may be the less expensive option for some private payers that pay at the $\$ 88$ or more rate.

Finally, the model found that SAM combined with PT provided superior outcome for the patient without the use of drugs or injections, and the modest incremental cost of care could provide significant cost savings for a life-long progressing disease; the ICER for SAM + PT versus NSAIDs +PT was found to be $\$ 15,576$.

\section{Limitations}

Medicare rates were assumed to be $75 \%$ of the commercial private payer rate-i.e., for every $\$ 1$ spent with Medicare, the commercial rate would be $\$ 1.33$. Commercial rates may be higher than this in some parts of the country based on negotiated rates between providers and payers, upwards of $100 \%$ higher with certain payers [67].

Costs used in the analysis were based off accepted treatment guidelines as identified by the American College of Rheumatology and were not prospectively captured [8]. As well, costs were assumed to be national averages and thus would vary by region of the country.

As mentioned above, opioid use was not evaluated, only topical NSAIDs. Topical NSAIDs were shown to be effective in relieving pain in identified systematic reviews and meta-analysis, and were used based on their short term positive effects. Longer term, some of these patients may be prescribed opioids. The risks of addiction to opioids (and associated costs and outcomes) were not evaluated. This could be evaluated in future studies.

No complication rates or costs of them were assumed for therapies used in the analysis. Considering many were very low, the cost and effect were assumed to be de minimize.

\section{Conclusion}

Based on accepted thresholds in determining the costeffectiveness of therapies in treating knee OA, SAM, wearable home-use continuous long duration ultrasound, appears to be a cost-effective therapy and should be considered when treating patients with knee OA.

\section{Supplementary information}

Supplementary information accompanies this paper at https://doi.org/10. 1186/s13018-020-01987-x.

Additional file 1:. Variable distributions

Additional file 2:. Equations used in model

\section{Abbreviations}

OA: Osteoarthritis; SAM: Sustained Acoustic Medicine; SOC: Standard of care; ICER: Incremental cost effectiveness ratio; PT: Physical therapy; ACR: America College Rheumatology; NSAID: Non-steroidal anti-inflammatory drug; VA: Veteran affairs; FDA: Federal Drug Administration; QoL: Quality of life

\section{Acknowledgements}

The authors would like to thank Mr. Jeff Voigt, MBA, MPH Wharton School, University of Pennsylvania, for assistance with health economic modeling and interpretation of results.

\section{Authors' contributions}

All authors contributed equally towards research and data analysis. The authors read and approved the final manuscript.

\section{Funding}

Research was supported by National Institutes of Health Grant \#5R44MD008597.

\section{Availability of data and materials}

https://pubmed.ncbi.nlm.nih.gov/ (pubmed.gov)

https://www.cochranelibrary.com/ (Google Scholar)

https://scholar.google.com/ (Cochrane Library)

Ethics approval and consent to participate Not applicable

Consent for publication Not applicable 


\section{Competing interests}

The authors declare that they have no competing interests.

\section{Author details}

'Department of Orthopedics, UHealth Sports Medicine Institute, University of Miami, Coral Gables, FL, USA. ${ }^{2}$ Orthopaedic Foundation, Stamford, CT, USA. ${ }^{3}$ Department of Orthopaedics, Albert Einstein College of Medicine, New York, NY, USA. ${ }^{4}$ Department of Orthopaedics, Weill Cornell Medical College, New York, NY, USA. ${ }^{5}$ Plancher Orthopaedics \& Sports Medicine, New York, NY, USA.

Received: 25 August 2020 Accepted: 27 September 2020

Published online: 19 October 2020

\section{References}

1. OA Prevalence and Burden, 2020 The Osteoarthritis Action Alliance: [Available from: https://oaaction.unc.edu/oa-module/oa-prevalence-andburden/.

2. Zhang Y, Jordan JM. Epidemiology of osteoarthritis. Clin Geriatr Med. 2010; 26(3):355-69.

3. Deshpande BR, Katz JN, Solomon DH, Yelin EH, Hunter DJ, Messier SP, et al. Number of Persons With Symptomatic Knee Osteoarthritis in the US: Impact of Race and Ethnicity, Age, Sex, and Obesity. Arthritis Care Res. 2016;68(12): 1743-50.

4. Andriacchi TP, Favre J, Erhart-Hledik JC, Chu CR. A systems view of risk factors for knee osteoarthritis reveals insights into the pathogenesis of the disease. Ann Biomed Eng. 2015;43(2):376-87.

5. Hadler NM. Knee pain is the malady--not osteoarthritis. Ann Intern Med. 1992;116(7):598-9.

6. Hochberg MC, Altman RD, April KT, Benkhalti M, Guyatt G, McGowan J, et al. American College of Rheumatology 2012 recommendations for the use of nonpharmacologic and pharmacologic therapies in osteoarthritis of the hand, hip, and knee. Arthritis Care Res. 2012;64(4):465-74.

7. Cleveland RJ, Luong ML, Knight JB, Schoster B, Renner JB, Jordan JM, et al. Independent associations of socioeconomic factors with disability and pain in adults with knee osteoarthritis. BMC Musculoskelet Disord. 2013;14:297.

8. Kolasinski SL, Neogi T, Hochberg MC, Oatis C, Guyatt G, Block J, et al. 2019 American College of Rheumatology/Arthritis Foundation Guideline for the Management of Osteoarthritis of the Hand, Hip, and Knee. Arthritis Care Res. 2020;72(2):149-62.

9. Rutjes AW, Nuesch E, Sterchi R, Juni P. Therapeutic ultrasound for osteoarthritis of the knee or hip. Cochrane Database Syst Rev. 2010;1: CD003132.

10. Zeng $C$, Li H, Yang T, Deng ZH, Yang Y, Zhang Y, et al. Effectiveness of continuous and pulsed ultrasound for the management of knee osteoarthritis: a systematic review and network meta-analysis. Osteoarthr Cartil. 2014;22(8):1090-9.

11. Zhang C, Xie Y, Luo X, Ji Q, Lu C, He C, et al. Effects of therapeutic ultrasound on pain, physical functions and safety outcomes in patients with knee osteoarthritis: a systematic review and meta-analysis. Clin Rehabil. 2016;30(10):960-71.

12. Zhou $X Y$, Zhang $X X$, Yu GY, Zhang ZC, Wang $F$, Yang $Y L$, et al. Effects of Low-Intensity Pulsed Ultrasound on Knee Osteoarthritis: A Meta-Analysis of Randomized Clinical Trials. Biomed Res Int. 2018;2018:7469197.

13. Aetna coverage policy \#0325; physical therapy [Available from: http://www. aetna.com/cpb/medical/data/300_399/0325.html.

14. CIGNA coverage policy \#0096 [Available from: https://cignaforhcp.cigna. com/public/content/pdf/coveragePolicies/medical/CPG135_Physical_ Therapy.pdf

15. CMS national coverage policy \#100-3 [Available from: https://www.cms.gov/ medicare-coverage-database/details/ncd-details.aspx?NCDId=58\&ncdver= $2 \& b c=$ AgAAQAAAAAAAAA\%3D\%3D\&.

16. Huang MH, Yang RC, Lee $\mathrm{CL}$, Chen TW, Wang MC. Preliminary results of integrated therapy for patients with knee osteoarthritis. Arthritis Rheum. 2005;53(6):812-20

17. Huang MH, Lin YS, Lee CL, Yang RC. Use of ultrasound to increase effectiveness of isokinetic exercise for knee osteoarthritis. Arch Phys Med Rehabil. 2005;86(8):1545-51.

18. Draper DO, Kahanov L, Prentice WE. Therapeutic ultrasound: McGraw-Hill Education; 2018
19. Draper DO, JLKKWK. Therapeutic modalities the art and science. third edition ed: Philadelphia; 2020.

20. Draper DO, Klyve D, Ortiz R, Best TM. Effect of low-intensity long-duration ultrasound on the symptomatic relief of knee osteoarthritis: a randomized placebo-controlled double-blind study. J Orthop Surg Res. 2018;13(1):257.

21. Langer MD, Lewis GK Jr. Sustained Acoustic Medicine: A Novel Long Duration Approach to Biomodulation Utilizing Low Intensity Therapeutic Ultrasound. Proc SPIE Int Soc Opt Eng. 2015;9467.

22. Langer MD, Levine V, Taggart R, Lewis GK, Hernandez L, Ortiz R. Pilot Clinical Studies of Long Duration, Low Intensity Therapeutic Ultrasound for Osteoarthritis. Proc IEEE Annu Northeast Bioeng Conf. 2014;2014.

23. Jack Masterson BK, Aaron Burdette, George Lewis Sr. Sustained Acoustic Medicine; Sonophoresis for Nonsteroidal Anti-inflammatory Drug Delivery in Arthritis. Therapeutic Delivery 2020.

24. Hawker GA, Stewart L, French MR, Cibere J, Jordan JM, March L, et al. Understanding the pain experience in hip and knee osteoarthritis--an OARSI/OMERACT initiative. Osteoarthr Cartil. 2008;16(4):415-22.

25. Bellamy N, Campbell J, Robinson V, Gee T, Bourne R, Wells G. Viscosupplementation for the treatment of osteoarthritis of the knee. Cochrane Database Syst Rev. 2006;2:CD005321.

26. Derry S, Conaghan P, Da Silva JA, Wiffen PJ, Moore RA. Topical NSAIDs for chronic musculoskeletal pain in adults. Cochrane Database Syst Rev. 2016;4:CD007400.

27. Loyola-Sanchez A, Richardson J, MacIntyre NJ. Efficacy of ultrasound therapy for the management of knee osteoarthritis: a systematic review with metaanalysis. Osteoarthr Cartil. 2010;18(9):1117-26.

28. Juni P, Hari R, Rutjes AW, Fischer R, Silletta MG, Reichenbach S, et al. Intraarticular corticosteroid for knee osteoarthritis. Cochrane Database Syst Rev. 2015;10:CD005328

29. ZetrOZ Systems national average reimbursement rates from payers for the SAM ultrasound device 2013-2020 [press release].

30. Veterans Administration Federal Supply Schedule SAM ultrasound device 2020 [Available from: https:/www.gsaadvantage.gov/ref_text/36F79720D0093/0V6 DZU.3QWQZA_36F79720D0093_MEDLOGFSS36F79720D0093.PDF.

31. CMS Fee Schedule [Available from: https://www.cms.gov/apps/physicianfee-schedule/search/search-criteria.aspx.

32. Report to the Congress. Medicare Payment Policy, March 2019 [Available from: http://www.medpac.gov/docs/default-source/reports/mar19_medpac_ entirereport sec.pdf.

33. Fransen M, McConnell S, Harmer AR, Van der Esch M, Simic M, Bennell KL. Exercise for osteoarthritis of the knee: a Cochrane systematic review. $\mathrm{Br} J$ Sports Med. 2015;49(24):1554-7.

34. Bannuru RR, Natov NS, Dasi UR, Schmid CH, McAlindon TE. Therapeutic trajectory following intra-articular hyaluronic acid injection in knee osteoarthritis--meta-analysis. Osteoarthr Cartil. 2011;19(6):611-9.

35. Sullivan GM, Feinn R. Using Effect Size-or Why the P Value Is Not Enough. J Grad Med Educ. 2012;4(3):279-82.

36. Turner MN, Hernandez DO, Cade W, Emerson CP, Reynolds JM, Best TM. The Role of Resistance Training Dosing on Pain and Physical Function in Individuals With Knee Osteoarthritis: A Systematic Review. Sports Health. 2020;12(2):200-6.

37. American Academy Of Orthopedic Surgeons 2017 work group committee on function and pain assessment [Available from: https://www.aaos.org/ osteoarthritisoftheknee2ndedition/.

38. CMS, Quality Measure Specifications [Available from: https://qpp.cms.gov/ docs/QPP_quality_measure_specifications/Claims-Registry-Measures/2019_ Measure_109_MedicarePartBClaims.pdf.

39. Waimann CA, Fernandez-Mazarambroz RJ, Cantor SB, Lopez-Olivo MA Zhang H, Landon GC, et al. Cost-effectiveness of total knee replacement: a prospective cohort study. Arthritis Care Res. 2014;66(4):592-9.

40. Incremental Cost Effectiveness Ratio Review, ICER value framework [Available from: https://icer-review.org/wp-content/uploads/2018/05/ICERvalue-framework-v1-21-18.pdf.

41. Lewis GK Jr, Langer MD, Henderson CR Jr, Ortiz R. Design and evaluation of a wearable self-applied therapeutic ultrasound device for chronic myofascial pain. Ultrasound Med Biol. 2013;39(8):1429-39.

42. Lewis GGS, Ortiz R. Wearable long-duration ultrasound treatment of chronic trapezius myalgia. J Pain. 2012;13:4.

43. Petterson S, Plancher K, Klyve D, Draper D, Ortiz R. Low-Intensity Continuous Ultrasound for the Symptomatic Treatment of Upper Shoulder and Neck Pain: A Randomized, Double-Blind Placebo-Controlled Clinical Trial. Journal of Pain Research. 2020 
44. Rigby JH, Taggart RM, Stratton KL, Lewis GK Jr, Draper DO. Intramuscular heating characteristics of multihour low-intensity therapeutic ultrasound. J Athl Train. 2015;50(11):1158-64.

45. BH DLM, Henry T, et al. The Effect of Low Intensity Wearable Ultrasound on Blood Lactate and Muscle Performance after High Intensity Resistance Exercise. J Exerc Physiol. 2017;20:14.

46. DO D. The Benefits of Long Duration Ultrasound. Biomedical Journal of Scientific \& Technical Research. Journal of Scientific \& Technical Research. 2019;18:4.

47. Taggart R, Langer MD, Lewis GK Jr. Human Factors Engineering and testing for a wearable, long duration ultrasound system self-applied by an end user. Conf Proc IEEE Eng Med Biol Soc. 2014;2014:554-7.

48. Dubois RW. Cost-effectiveness thresholds in the USA: are they coming? Are they already here? J Comp Eff Res. 2016;5(1):9-11.

49. Kamaruzaman $H$, Kinghorn $P$, Oppong R. Cost-effectiveness of surgical interventions for the management of osteoarthritis: a systematic review of the literature. BMC Musculoskelet Disord. 2017;18(1):183.

50. Araujo IL, Castro MC, Daltro C, Matos MA. Quality of life and functiona independence in patients with osteoarthritis of the knee. Knee Surg Relat Res. 2016;28(3):219-24

51. Pain. functional disability and quality of life in knee osteoarthritis. Int J Health Sci Res. 2018;8(7):177-81.

52. Julia-Rahela M, CA SP, Sanda PR. Correlations between functional status and the quality of life in patients with knee osteoarthritis. Annals Phys Rehab Med. 2014;57:e38.

53. Pinto D, Robertson MC, Hansen P, Abbott JH. Cost-effectiveness of nonpharmacologic, nonsurgical interventions for hip and/or knee osteoarthritis: systematic review. Value Health. 2012;15(1):1-12.

54. American College of Surgeons, Medicare Coverage for Virtual Services. [Available from: https://www.facs.org/covid-19/legislative-regulatory/ telehealth/medicare-coverage.

55. CMS, Medicare Fee-For-Service (FFS) Response to the Public Health emergency on the Coronavirus (COVID-19) [Available from: https://www. cms.gov/files/document/se20011.pdf.

56. McAlindon TE, Bannuru RR, Sullivan MC, Arden NK, Berenbaum F, BiermaZeinstra SM, et al. OARSI guidelines for the non-surgical management of knee osteoarthritis. Osteoarthr Cartil. 2014;22(3):363-88.

57. American Academy of Orthopaedic Surgeons, Osteoarthritis of the knee [Available from: https://www.aaos.org/quality/quality-programs/lowerextremity-programs/osteoarthritis-of-the-knee/.

58. Optum Policy \#363. Utilization management policy. The application of passive modalities for neuromusculoskeletal disorders [Available from: https://www.myoptumhealthphysicalhealth.com/ClinicalPolicies/363.pdf.

59. Best TM, Moore B, Jarit P, Moorman CT, Lewis GK. Sustained acoustic medicine: wearable, long duration ultrasonic therapy for the treatment of tendinopathy. Phys Sportsmed. 2015;43(4):366-74.

60. Draper DMC, Henderson S, Wilk K, Lewis GK. A novel therapeutic modality for sustained deep tissue heating and accelerating tendon recovery. Physiotherapy. 2015.

61. Stratton K, Taggart R, Lewis GK. Long duration ultrasound facilitates delivery of a therapeutic agent. J Acoust Soc Am. 2014:4(136):1.

62. Power JD, Perruccio AV, Gandhi R, Veillette C, Davey JR, Lewis SJ, et al. Factors Associated With Opioid Use in Presurgical Knee, Hip, and Spine Osteoarthritis Patients. Arthritis Care Res. 2019;71(9):1178-85.

63. Wei W, Gandhi K, Blauer-Peterson C, Johnson J. Impact of pain severity and opioid use on health care resource utilization and costs among patients with knee and hip osteoarthritis. J Manag Care Spec Pharm. 2019;25(9):957-65.

64. Rhon DI, Snodgrass SJ, Cleland JA, Greenlee TA, Sissel CD, Cook CE. Comparison of downstream health care utilization, costs, and long-term opioid use: physical therapist management versus opioid therapy management after arthroscopic hip surgery. Phys Ther. 2018;98(5):348-56.

65. Kumar D PC, Stokes A, Marinko L, Camarinos J, Felson D, Dubreuil M. Physical therapy and opioid use in knee osteoarthritis. Arthritis Rheumatol; 20192019.

66. Department of Health and Human Services, About the Epidemic [Available from: https://www.hhs.gov/opioids/about-the-epidemic/index.html.

67. Congressional Budget Office, An Analysis of Private-Sector Prices for Physician Services [cited 2020 8/10/20]. Available from: https:/www.cbo.gov/system/ files/115th-congress-2017-2018/presentation/52818-dp-presentation.pdf.

\section{Publisher's Note}

Springer Nature remains neutral with regard to jurisdictional claims in published maps and institutional affiliations.

\section{Ready to submit your research? Choose BMC and benefit from}

- fast, convenient online submission

- thorough peer review by experienced researchers in your field

- rapid publication on acceptance

- support for research data, including large and complex data types

- gold Open Access which fosters wider collaboration and increased citations

- maximum visibility for your research: over $100 \mathrm{M}$ website views per year

At $\mathrm{BMC}$, research is always in progress.

Learn more biomedcentral.com/submissions 